\title{
Synthesis and properties of poly(hexamethylene terephthalate)/multiwall carbon nanotubes nanocomposites
}

\author{
Nathalie González-Vidal, ${ }^{\mathrm{a}}$ Antxon Martínez de Ilarduya, ${ }^{\mathrm{a}}$ Sebastián Muñoz-Guerra, ${ }^{\text {a* }}$ \\ Pere Castell $^{\mathrm{b}}$ and María Teresa Martínez ${ }^{\mathrm{b}}$ \\ ${ }^{a}$ Departament d'Enginyeria Química, Universitat Politècnica de Catalunya, ETSEIB, \\ Diagonal 647, 08028-Barcelona, Spain

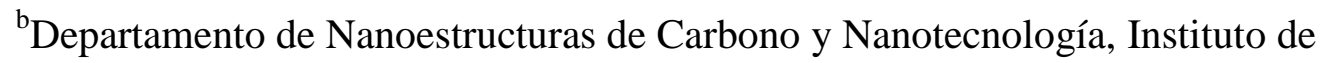 \\ Carboquímica de Zaragoza, CSIC, 50018-Zaragoza, Spain
}

\begin{abstract}
Poly(hexamethylene terephthalate) (PHT)/carbon nanotubes (CNT) nanocomposites containing $1 \%$ and $3 \%(\mathrm{w} / \mathrm{w})$ of filler were prepared by two procedures: in situ ring-opening polymerization of hexamethylene terephthalate cyclic oligomers in the presence of CNT and melt blending of PHT/CNT mixtures. Arc discharge multiwalled carbon nanotubes, both pristine (MWCNT) and hydroxyl functionalized (MWCNT-OH), were used. The objective was to evaluate the effect of preparation procedure, nanotube sidewall functionalization and amount of nanotube loaded on properties of PHT. All nanocomposites showed an efficient distribution of the carbon nanotubes within the PHT matrix but interfacial adhesion and reinforcement effect was dependent on both functionalization and nanotubes loading. Significant differences in thermal stability and mechanical properties ascribable to functionalization and processing were observed among the prepared nanocomposites. All the prepared nanocomposites showed enhanced crystallizability due to CNT nucleating effects although changes in melting and glass transition temperatures were not significant.
\end{abstract}




\section{Introduction}

Since their discovery in 1991 [1], carbon nanotubes (CNT) have attracted great attention owing to their unique structure and exceptional physical properties. The outstanding mechanical behavior, extremely large interfacial contact area, high aspect ratio, and low mass density of CNT make them ideal reinforcement filler for nanocomposite materials [2]. Along these last years it has become evidenced that advanced multifunctional composite materials can be satisfactorily prepared by the incorporation of nanotubes in different polymer matrices [3].

Great efforts are being recently addressed to the preparation of aromatic polyester nanocomposites with the aim of improving the properties of these materials and spreading their use. Poly(hexamethylene terephthalate) (PHT) is a non-commercial aromatic polyester of both academic and applied interest. As it is characteristic of semicrystalline aromatic polyesters, PHT exhibits fair mechanical properties, an excellent chemical resistance [4]. Due to the presence of the flexible hexamethylene segment in the polyester chain, PHT has a relatively low $T_{\mathrm{m}}\left(\sim 140{ }^{\circ} \mathrm{C}\right)$, which could be regarded as advantageous for a more economical and easier processing [5-6]. In the present work PHT nanocomposites containing multiwall nanotubes both $\mathrm{OH}-$ functionalized and without functionalization are prepared and characterized. The objective is to evaluate the effect of multiwalled carbon nanotubes on the basic properties of PHT taking into account both the amount loaded and side-wall functionalization.

When successful, the influence of nanotubes on the polymer matrix is markedly reflected on morphology [7], crystallinity [8], and thermo-mechanical properties $[9,10]$. However such positive effects are by no means always observed due to the difficulties encountered in dispersing adequately the nanotube bundles in the highly viscous 
polymer matrix, which is essential for ensuring a good interfacial stress transfer between the two components [11]. Three methods are usually applied to produce polymer/carbon nanotubes nanocomposites, i.e., solution mixing [12], melt blending [13], and in situ polymerization of monomers or oligomers in the presence of the nanotubes [14]. These last two methods are applied in this work to prepare the PHT/CNT nanocomposites and results obtained therefrom are compared and critically discussed.

\section{Experimental}

\subsection{Materials}

The solvents used for purification and characterization, such as chloroform, dichloroacetic acid (DCA) and 1,1,1,3,3,3-hexafluoro-2-propanol (HFIP), were highpurity grade and used as received. Poly(hexamethylene terephthalate) was synthesized by conventional melt polycondensation of 1,6-hexanediol (HD) with dimethyl terephthalate (DMT). Hexamethylene terephthalate cyclic oligomers $c(\mathrm{HT})_{\mathrm{n}}$ with $\mathrm{n}=2-7$ were obtained by cyclo-depolymerization of PHT. The procedures for these two syntheses have been recently described in full detail and applied here with minor modifications [4]. Multiwalled carbon nanotubes (MWCNT) were produced by electricarc discharge and their functionalization performed as it is shown in Scheme 1. In brief, MWCNT were oxidized with $\mathrm{HNO}_{3} / \mathrm{H}_{2} \mathrm{SO}_{4} 3 / 1(\mathrm{v} / \mathrm{v})$ during $1 \mathrm{~h}$ at $100{ }^{\circ} \mathrm{C}$ to obtain the carboxyl-functionalized nanotubes (MWCNT-COOH). The MWCNT-COOH were then made to react with an excess of $\mathrm{SOCl}_{2}$ under reflux during $24 \mathrm{~h}$ to obtain the acyl chloride derivative (MWCNT-COCl). The acyl chloride-functionalized nanotubes were dispersed in 1,4-butanediol adding $3 \mathrm{~mL}$ of pyridine and the dispersion maintained at 
$100{ }^{\circ} \mathrm{C}$ for 3 days under vigorous stirring to finally obtain the hydroxyl-functionalized nanotubes (MWCNT-OH).

\subsection{Nanocomposite preparation by in situ ring-opening polymerization}

Nanotubes, either functionalized or without functionalizing, and cyclic oligomers $c(\mathrm{HT})_{2-7}$ used for nanocomposite preparation were previously dried overnight at $60{ }^{\circ} \mathrm{C}$ in a ventilated oven. The nanotubes were suspended in chloroform $\sim 0.2 \%(\mathrm{w} / \mathrm{v})$ and the suspension was sonicated for $30 \mathrm{~min}$ at $0{ }^{\circ} \mathrm{C}$ and then mixed with a $10 \%(\mathrm{w} / \mathrm{v})$ solution of $c(\mathrm{HT})_{2-7}$ in chloroform. All sonication treatments were carried out in a Sonoplus HD2200 ultrasonic homogenizer (Bandelin, Germany) with a cylindrical tip MS72 (2 $\mathrm{mm}$ end cap diameter) at the frequency of $20 \mathrm{KHz}$. The solvent was slowly evaporated under vigorous stirring and the residue was dried at $50{ }^{\circ} \mathrm{C}$ under reduced pressure for 24 h. The solid mixture of cyclic oligomers $c(\mathrm{HT})_{2-7}$ and nanotubes was added with $\mathrm{Sb}_{2} \mathrm{O}_{3}$ (0.5\%-mole) and introduced into a flask equipped with a nitrogen inlet/outlet. The flask was purged with nitrogen to remove all traces of moisture and residual air, and immersed in an oil heating bath and the reaction carried out at $200{ }^{\circ} \mathrm{C}$ for $30 \mathrm{~min}$. The final reaction mixture was quenched in an ice-water bath and the atmospheric pressure was recovered using nitrogen to prevent degradation. A similar procedure was followed for the polymerization of $c(\mathrm{HT})_{2-7}$ to obtain the PHT used for reference.

\subsection{Nanocomposite preparation by melt blending}

Nanotubes, either functionalized or without functionalizing, were dried and mixed with PHT and the mixture was introduced through the addition funnel into a Minilab twin-screw mini-extruder (Haake Minilab Thermo-Electron Corporation, USA) equipped with two counter-rotating screws and a closed loop for recirculation. The mini-extruder temperature was set at $150^{\circ} \mathrm{C}$ and the mixture was left under recirculation 
for 3 min applying a rotating screw speed of $60 \mathrm{rpm}$ which was then increased to 90 rpm for $10 \mathrm{~min}$. The nanocomposite was recovered through the die and cooled down to room temperature. For comparative purposes PHT was also processed by applying exactly the same procedure.

\subsection{Characterization}

Molecular weight analyses were performed by gel permeation chromatography (GPC) using HFIP containing sodium trifluoroacetate $\left(6.8 \mathrm{~g} \cdot \mathrm{L}^{-1}\right)$ in a Waters equipment provided with RI and UV detectors. $100 \mu \mathrm{L}$ of $0.1 \%(\mathrm{w} / \mathrm{v})$ sample solution were injected under a flow of $0.5 \mathrm{~mL} \cdot \mathrm{min}^{-1}$. HR5E and HR2 Waters linear Styragel columns packed with crosslinked polystyrene and protected with a precolumn were used. Molecular weight averages and distributions were evaluated against PMMA standards. Intrinsic viscosities from polymer solutions were measured in DCA using an Ubbelohde viscometer thermostatted at $25.0 \pm 0.1{ }^{\circ} \mathrm{C}$. For molecular weight measurements, the nanocomposite was suspended in the corresponding solvent and the suspension filtered to remove the free CNT (not covalently attached to the polymer) prior to GPC and viscosity determination.

The thermal behavior of cyclic compounds and polymers was examined by differential scanning calorimetry (DSC), using a Perkin-Elmer Pyris 1 apparatus, at heating and cooling rates of $10{ }^{\circ} \mathrm{C} \cdot \mathrm{min}^{-1}$ under a nitrogen flow of $20 \mathrm{~mL} \cdot \mathrm{min}^{-1}$. Thermogravimetric analysis (TGA) was carried out with a Perkin Elmer TGA-6 thermobalance at a heating rate of $10^{\circ} \mathrm{C} \cdot \mathrm{min}^{-1}$ under an air atmosphere. Raman spectra were recorded in a micro-Raman instrument T64000 of Jobin Yvon which consists of an Olympus optical microscope combined with a triple monochromador dispersive system and a CCD detector cooled at liquid nitrogen temperature. Scanning electron microscopy (SEM) microphotographs were taken with a JEOL SSM-6400 instrument 
from film samples prepared by melt compression (see details below) fractured in liquid nitrogen. Gold coating was accomplished by using a Balzers SDC-004 Sputter Coater. X-ray diffraction experiments were carried out at the CRG-BM16 beamline of ESRF synchrotron in Grenoble (FR) from powdered samples using semicrystalline standard PET for calibration.

Tensile tests were conducted at room temperature using a Zwick BZ2.5/TN1S universal tensile testing apparatus operating at a constant crosshead speed of 10 $\mathrm{mm} \cdot \mathrm{min}^{-1}$ using a $0.5-\mathrm{N}$ preload and a grip-to-grip separation of $20 \mathrm{~mm}$. All reported tensile data represent an average of at least six independent measurements. Mechanical testing was performed on melt compressed samples of rectangular shape 4 mm-width and an average thickness of $0.16 \mathrm{~mm}$.

\section{Results and discussion}

\subsection{Nanotubes functionalization and nanocomposites synthesis}

The reaction sequence corresponding to MWCNT functionalization is depicted in Scheme 1. The TGA profile of MWCNT-OH revealed a considerably higher weight loss in the temperature range $200-500{ }^{\circ} \mathrm{C}$ than for MWCNT which is made to correspond to the thermal disruption of the alkyl attachments (Figure 1a). In the Raman spectra (Figure 1b), the disorder band intensity (D peak) has increased notably for MWCNT$\mathrm{OH}$ as compared to the original MWCNT in agreement with should be expected for functionalization of the MWCNT with 1,4-butanediol. TEM observations of extended preparations of nanotubes showed that the diameters of both MWCNT and MWCNT$\mathrm{OH}$ were within the $10-25 \mathrm{~nm}$ range indicating that aggregation due to possible internanotube esterification should not be significant. It can be observed that the MWCNT are straight and highly graphitized, which is typical of high temperature produced arc 
discharge CNTs. The pristine MWCNT (Figure 1c) showed no presence of amorphous carbon on the surface and very low number of defects. On the other hand functionalized MWCNT (Figure 1d) showed some deposits on the surface of the tubes that can be attributed to oxidation and functionalization.

The two procedures applied here to prepare the nanocomposites are depicted in Scheme 2 and some characterization data are given in Table 1. PHT synthesized by ROP under identical conditions to those used for the preparation of the nanocomposites had an intrinsic viscosity of $0.67 \mathrm{dL} \cdot \mathrm{g}^{-1}$ and a $M \mathrm{w} \sim 40,000 \mathrm{~g} \cdot \mathrm{mol}^{-1}$ with a polydispersity around 2 . The PHT obtained by polycondensation to be used for melt blending had an intrinsic viscosity of $0.71 \mathrm{dL} \cdot \mathrm{g}^{-1}$ and a $M \mathrm{w} \sim 55,000 \mathrm{~g} \cdot \mathrm{mol}^{-1}$ with a polydispersity of 2.0. The viscosity values for nanocomposites prepared by ROP slightly decreased as a result of the presence of CNT in the polymerization. Conversely the viscosity of melt blending nanocomposites remains almost unaffected.

Data provided by the thermogravimetry analysis are summarized also in Table 1. All materials showed one main decomposition step obviously corresponding to PHT decomposition, which begins to degrade at approximately $375^{\circ} \mathrm{C}$ to be completely decomposed at $550{ }^{\circ} \mathrm{C}$ (Figure 2). It was observed that the addition of $1 \%(\mathrm{w} / \mathrm{w})$ of MWCNT increased the temperature of maximum weight loss rate (measured on the first derivative curve) of PHT in $\sim 15{ }^{\circ} \mathrm{C}$, this value remaining essentially constant for further increase in filler content. Conversely, addition of functionalized carbon nanotubes only increased the temperature of maximum decomposition rate in $\sim 10{ }^{\circ} \mathrm{C}$. A similar behavior was observed for the nanocomposites prepared by melt blending although the effect was a more attenuated. 


\subsection{Morphological observations}

Scanning electron microscopy provided clear indications about the dispersion of the MWCNT in the polymer matrix (Figure 2). A high degree of dispersion of the pristine nanotubes in the nanocomposites was attained by using any of the two procedures (Figures 2a and 2c); a fairly homogeneous distribution of individual MWCNT throughout the matrix was observed although the images of the fracture surfaces reveal frequent pulling out of the nanotubes from the polymer indicative that the interfacial interaction between the two components is poor. Conversely, identification of functionalized nanotubes in the matrix in nanocomposites ropPHT/MWCNT-OH and $b d \mathrm{PHT} / \mathrm{MWCNT}-\mathrm{OH}$ is much more difficult without almost occurrence of protruding isolated nanotubes (Figure $2 \mathrm{~b}$ and $2 \mathrm{~d}$ ); in these nanocomposites, the nanotubes appear fully covered with PHT and deeply embedded in the matrix. As expected, chemical functionalization provided greater compatibilization between the modified nanotubes and the polymer allowing a greater interfacial adhesion. Noticeable differences in fracture morphology of nanocomposites depending on MWCNT loading were also observed, the nanocomposites with lower nanotubes loading showing the most efficient polymer reinforcement. In this material in fact the nanotubes appear broken on the fracture surfaces indicating a very effective load transfer from matrix to nanotubes (Figure 2e).

\subsection{Mechanical properties of nanocomposites}

The mechanical properties of the PHT nanocomposites were found to be dependent on the amount of loaded nanotubes and even more, on the degree of dispersion that is attained in the nanocomposite. Table 1 shows the tensile test data for the different studied composite materials. As it is shown in Figure 3, the presence of nanotubes does not alter the overall mechanical pattern of behavior of PHT. What is really remarkable 
is that incorporation of nanotubes, for whichever type used and preparation method applied, led to a significant increase in the Young's modulus. In the case of the nanocomposites prepared by the in situ ROP procedure, the observed increase in the Young modulus is particularly significant due to the lower polymerization degree that the PHT has in this case (lower viscosity observed) indicating that the effect of the MWCNT loading is even higher. This effect is more pronounced for functionalized nanotubes with an increase of more than $100 \%$ for the ropPHT/MWCNT-OH $3 \%$ $(\mathrm{w} / \mathrm{w})$; this result is consistent with the greater interfacial contact attained for the nanocomposites prepared from these nanotubes.

The changes observed in stress and strain at break of PHT upon addition of nanotubes were not as consistent as those observed for the elastic modulus. In general, the ultimate elongation of PHT decreased significantly with the amount of added filler dropping off to around $25 \%$ of the original value for the nanocomposites containing $3 \%$ (w/w) of MWCNT. This reduction in elongation was more moderated (only to 50\%) in the case that modified nanotubes were used. The stress at break was no so sensitive to the nanotube loading as the other mechanical parameters and displayed an uneven response regarding composition; it increased for $1 \%(\mathrm{w} / \mathrm{w})$ of nanotubes load but decreased more or less notably when the content of filler increased

\subsection{Melting and crystallization of nanocomposites}

The effect of CNT addition on PHT melting and crystallization was examined by DSC (Figure 4) and recorded data are listed in Table 2. All the samples exhibit a single crystallization exotherm and a single or double melting endotherm depending of the filler used. No significant differences in either $T_{m}$ or $T_{g}$ were observed upon nanotube addition. On the contrary, $T_{c}$ was found to increase, such increasing being even more noticeable for nanocomposites made from unfunctionalized nanotubes. This result 
evidences the nucleating effect of MWCNT, which appears to be more pronounced in the case of pristine nanotubes. Nevertheless, the effect of CNT on crystallinity was small; increases in the melting enthalpy of less than $10 \%$ were observed in the most favorable case.

A double peak endotherm is observed for the melting of neat PHT as well as for the PHT in nanocomposites made from MWCNT-OH. On the contrary, PHT crystallized in the presence of unfunctionalized nanotubes, MWCNT, displays a single peak melting endotherm. Multiple peak melting in polymer is a common phenomenon that is usually attributed either to the presence of crystallite populations differing in sizes or to the occurrence of a process of melting-crystallization-remelting taking place at heating. Nevertheless, the complex melting behavior of PHT has been studied extensively and some authors have related it with the presence of crystal polymorphism. In fact, PHT tends to adopt two crystal forms, designated as $\alpha$ - and $\beta$-forms $[5,6,15]$ depending on its thermal history, which are difficult to separate to each other. The WAXS profiles recorded from PHT and nanocomposites (not shown here) were essentially identical with most prominent reflection peaks at $2 \theta=15.8,18.1,21.0,22.6$, and $23.9^{\circ}$. According to available reported data $[15,16]$, these peaks arise from the $\beta$ crystal form of PHT that usually is generated after the heat-treatment.

A comparative isothermal crystallization study of materials to evaluate the crystallizability in more detail was performed by DSC. The crystallization plots displaying the evolution of the relative crystallinity with time are depicted in Figure 5a and $5 \mathrm{c}$ for the two series at the crystallization temperatures of $132.5^{\circ} \mathrm{C}$ and $135{ }^{\circ} \mathrm{C}$, respectively. The corresponding double logarithmic Avrami plots for the crystalinity range of 0.4-1.0 are depicted in Figure 5b and 5d. The Avrami treatment [17] of these data led to determine the isothermal crystallization parameters $K$ and $n$, as well as the 
half-crystallization time $t_{1 / 2}$ (Table 2 ). As expected, crystallization rate decreased with crystallization temperature reflecting a regular increasing of crystallization half-times for increasing values of $T_{\mathrm{c}}$ (results not shown). What was clearly revealed in this study is that nanotube addition speeded up crystallization for both ROP and melt-blending prepared nanocomposites and that this effect increased with nanotube loading but diminished with functionalization. The weaker nucleating effect of functionalized CNT compared to the pristine ones could be ascribed to the smaller effective CNT surface remaining after attachment of the grafted polymer. Roughly similar changes were found for nanocomposites obtained by the two procedures. As seen in Table 2, the Avrami exponent of neat PHT with a value close to 2 changed to values between 1.9 and 1.5 upon nanotube addition. The trend observed is that $n$ goes towards lower values as the content in CNT increases. This trend is shared by nanocomposites prepared by the two methods and whichever type of nanotube used. As it is generally accepted, Avrami exponents about 2 are interpreted as arising from the material crystallized by heterogeneous nucleation in two-dimensional morphologies. Although the trend observed for $n$ with composition changes is clear, no definite conclusions can be drawn at this stage; in fact, observations previously reported in this regard by other authors are not in full agreement.[18,19]

\section{Conclusions}

Poly(hexamethylene terephthalate) multiwalled carbon nanotubes nanocomposites were prepared by dispersing MWCNT or modified MWCNT-OH nanotubes into PHT by two procedures, in situ ring-opening polymerization of cyclic hexamethylene oligomers and melt blending of the CNT with the PHT in the melt. Well dispersed materials were obtained by the two procedures although functionalization was proved to 
be decisive to attain a satisfactory compatibilization. Changes in mechanical properties of the nanocomposites concerned mainly the elastic modulus with an increase in the stiffness that attained $100 \%$ for nanocomposites prepared by ROP with $3 \%(\mathrm{w} / \mathrm{w})$ of MWCNT-OH. The thermal stability of nanocomposites was slightly improved whereas changes in $T_{m}$ and $T_{g}$ were almost negligible. Conversely a significant increase in melting enthalpy and crystallization temperature of PHT was observed upon addition of either MWCNT or MWCNT-OH nanotubes. The comparative Isothermal crystallization study revealed that nanocomposites crystallized at higher rates than PHT and that the rate increased with the amount of nanotubes loaded. The final conclusion of this work is that reinforcement of PHT with MWCNT affords thermally stable materials with improved mechanical properties and enhanced crystallizability, effects that are more efficiently attained when they are prepared by ROP and functionalized CNT are used.

\section{Acknowledgements}

We thank the CICYT (Comisión Interministerial de Ciencia y Tecnología) of Spain for financial support (Grant MAT2006-13209-C02-02) and AGAUR for the Ph.D. grant awarded to Nathalie González-Vidal. The support given by La Seda de Barcelona SA (El Prat, Barcelona) is also gratefully acknowledged.

\section{References}

[1] Iijima S. Helical microtubules of graphitic carbon. Nature 1991;354:56-8.

[2] Ajayan PM, Suhr J, Koratkar N. Utilizing interfaces in carbon nanotube reinforced polymer composites for structural damping. J. Mater. Sci. 2006;41:7824-9. 
[3] Ma H, Zeng J, Realff ML, Kumar S, Schiraldi DA. Processing, structure, and properties of fibers from polyester/carbon nanofiber composites. Comp Sci Technol 2003;63:1617.

[4] Gonzalez-Vidal N, Martínez de Ilarduya A, Herrera V, Muñoz-Guerra S. Poly(hexamethylene terephthalate-co-caprolactone) copolyesters obtained by ring-opening polymerization. Macromolecules 2008;41:4136-46.

[5] David C, Lefèbvre X, Lefèvre C, Demarteau W, Loutz JM. Thermal behaviour of polyesters of hexanediol with terephthalic and isophthalic acids. Prog Org Coat $1999 ; 35: 45-54$.

[6] Lefèbvre X, Koch MHJ, Reynaers H, David C. Thermal behavior of poly(hexamethylene terephthalate) oligomers I. Melting behavior and morphology of the crystalline phase. J Polym Sci Polym Phys 1999;37:1-18.

[7] Gao C, Vo CD, Jin YZ, Li W, Armes SP. Multihydroxy polymer-functionalized carbon nanotubes: synthesis, derivatization, and metal loading. Macromolecules 2005;38:8634-48.

[8] Tzavalas S, Drakonakis V, Mouzakis DE, Fischer D, Gregoriou VG. Effect of carboxy-functionalized multiwall nanotubes (MWNT-COOH) on the crystallization and chain conformations of poly(ethylene terephthalate) PET in PET-MWNT nanocomposites Macromolecules 2006;39:9150-6.

[9] Gojny FH, Schulte K. Functionalisation effect on the thermo-mechanical behaviour of multi-wall carbon nanotube/epoxy-composites. Comp Sci Technol 2004;64:2303-8.

[10] Koval'chuk AA, Shevchenko VG, Shchegolikhin AN, Nedorezova PM, Klyamkina AN, Aladyshev AM. Effect of carbon nanotube functionalization on 
the structural and mechanical properties of polypropylene/MWCNT composites. Macromolecules 2008;41:7536-42.

[11] Salvetat JP, Bhattacharyya S, Pipes, RB. Progress on mechanics of carbon nanotubes and derived materials. J Nanosci. Nanotech; 2006, 6:1857-82

[12] Lamy de la Chapelle M, Stephan C, Nguyen TP, Lefrant S, Journet C, Bernier P, Munoz E, Benito A, Maser WK, Martinez MT, de la Fuente GF, Guillard T, Flamant G, Alvarez L, Laplaze D. Raman characterization of singlewalled carbon nanotubes and PMMA-nanotubes composites. Synth Met $1999 ; 103: 2510-2$

[13] Zhang WD, Shen L, Phang IY, Liu T. Carbon nanotubes reinforced nylon-6 composite prepared by simple melt-compounding. Macromolecules 2004;37: 256-9.

[14] a) Broza G, Kwiatkowska M, Rosłaniec Z, Schulte K. Processing and assessment of poly(butylene terephthalate) nanocomposites reinforced with oxidized single wall carbon nanotubes. Polymer 2005;46:5860-7. b) Baets J, Godara A, Devaux J, Verpoest I. Toughening of polymerized cyclic butylene terephthalate with carbon nanotubes for use in composites. Composites Part A 2008;39:1756-61.

[15] Wu MC, Woo EM, Yoshioka T, Tsuji M. Thermal analysis, X-ray and electron diffraction studies on crystalline phase transitions in solvent-treated poly(hexamethylene terephthalate). Polymer 2006;47:5523-30.

[16] Woo E, Wu PL, Chiang CP, Liu HL. Analysis of polymorphism and dual crystalline morphologies in poly(hexamethylene terephthalate). Macromol Rapid Comm 2004;25:942-8. 
[17] Avrami M. Kinetics of phase change. I General Theory. J Chem Phys 1939;7:1103.

[18] Haggenmueller R, Fischer JE, Winey KI. Single wall carbon nanotube/polyethylene nanocomposites: nucleating and templating polyethylene crystallites Macromolecules 2006;39:2964-71.

[19] Grady B P; Pompeo F; Shambaugh RL; Resasco DE. Nucleation of polypropylene crystallization by single-walled carbon nanotubes. J Phys Chem B 2002;106:5852-8.

\section{Figure captions}

Scheme 1. Chemical process applied for hydroxyl functionalization of multiwalled carbon nanotubes.

Scheme 2. Schematic representation of the two approaches used to prepare the PHT nanocomposites.

Figure 1. Pristine and $\mathrm{OH}$-functionalized carbon nanotubes compared. a) Raman spectra, b) TGA profiles, TEM micrographs of c) pristine MWCNT and d) MWCNT$\mathrm{OH}$.

Figure 2. Compared TGA profiles of the indicated nanocomposites (a), and their respective derivative curves (b).

Figure 3. SEM micrographs of the PHT nanocomposites: (a) and (b), ropPHT/MWCNT 3\% (w/w) and ropPHT/MWCNT-OH 3\% (w/w), (c) and (d) $b d$ PHT/MWCNT and bdPHT/MWCNT-OH 3\% (w/w). (e) ropPHT/MWCNT-OH $1 \%(\mathrm{w} / \mathrm{w})$.

Figure 4. Compared stress-strain curves of nanocomposites obtained by ROP (a) and by melt blending (b) for the indicated compositions. 
Figure 5. DSC cooling and heating scans for PHT nanocomposites obtain by ROP (a and $\mathrm{b}$ ) and by melt blending ( $\mathrm{c}$ and $\mathrm{d}$ ) for the indicated compositions.

Figure 6. Fractional degree of crystallinity $v s$ crystallization time (a and c) and plot of $\log \left(-\operatorname{Ln}\left(1-X_{\mathrm{t}}\right)\right)$ vs $\log \left(\mathrm{t}-\mathrm{t}_{0}\right)$ (b and $\left.\mathrm{d}\right)$ for isothermal crystallization of nanocomposites prepared by ROP by melt blending.

Table 1

Thermal and mechanical properties of PHT nanocomposites.

\begin{tabular}{lccccccc}
\hline Sample & {$[\eta]^{\mathrm{a}}$} & $\begin{array}{l}{ }^{\mathrm{o}} T_{\mathrm{d}}^{\mathrm{b}} \\
\left({ }^{\circ} \mathrm{C}\right)\end{array}$ & $\begin{array}{l}{ }^{\mathrm{o}} T_{\mathrm{d}} \mathrm{b} \\
\left({ }^{\circ} \mathrm{C}\right)\end{array}$ & $\begin{array}{l}\mathrm{RW}^{\mathrm{b}} \\
(\%)\end{array}$ & $\begin{array}{l}\text { Young } \\
\text { modulus }^{\mathrm{c}} \\
(\mathrm{MPa})\end{array}$ & $\begin{array}{l}\text { Stress } \\
\text { break }^{\mathrm{c}} \\
(\mathrm{MPa})\end{array}$ & $\begin{array}{l}\text { at Strain at } \\
\text { break }^{\mathrm{c}} \\
(\%)\end{array}$ \\
\hline ropPHT & 0.67 & 374 & 399 & 1.9 & 531 & 15.4 & 3.32 \\
ropPHT/MWCNT 1\% & 0.65 & 383 & 406 & 2.1 & 890 & 20.8 & 2.18 \\
ropPHT/MWCNT 3\% & 0.62 & 384 & 407 & 2.3 & 961 & 11.3 & 0.85 \\
ropPHT/MWCNT-OH 1\% & 0.64 & 385 & 413 & 2.2 & 963 & 20.8 & 2.65 \\
ropPHT/MWCNT-OH 3\% & 0.62 & 385 & 412 & 2.4 & 1047 & 19.9 & 1.81 \\
& & & & & & & \\
bdPHT & 0.72 & 380 & 405 & 1.1 & 740 & 19.5 & 3.07 \\
bdPHT/MWCNT 1\% & 0.71 & 383 & 410 & 1.0 & 1005 & 19.5 & 1.89 \\
bdPHT/MWCNT 3\% & 0.72 & 384 & 411 & 1.2 & 1045 & 10.5 & 0.73 \\
bdPHT/MWCNT-OH 1\% & 0.72 & 385 & 413 & 1.2 & 1135 & 20.9 & 2.22 \\
bdPHT/MWCNT-OH 3\% & 0.72 & 384 & 414 & 1.4 & 1183 & 16.9 & 1.56 \\
\hline
\end{tabular}

${ }^{a}$ Intrinsic viscosity in DCA at $25^{\circ} \mathrm{C}$.

${ }^{\mathrm{b}}$ Onset (10\% of weight loss), maximum rate decomposition temperatures and residual weight at $700{ }^{\circ} \mathrm{C}$ determined by TGA under air atmosphere.

${ }^{c}$ Tensile test performed at $20^{\circ} \mathrm{C}$ applying a constant deformation rate of $50 \mathrm{~mm} \cdot \mathrm{min}^{-1}$. 
Table 2

Melting temperatures and enthalpies, crystallization temperatures, and crystallinity degrees of PHT nanocomposites.

\begin{tabular}{|c|c|c|c|c|c|c|c|c|c|c|}
\hline & $T_{\mathrm{g}}^{\mathrm{a}}\left({ }^{\circ} \mathrm{C}\right)$ & $T_{\mathrm{c}}^{\mathrm{b}}\left({ }^{\mathrm{o}} \mathrm{C}\right)$ & $T_{\mathrm{m}}{ }^{\mathrm{c}}\left({ }^{\circ} \mathrm{C}\right)$ & $\Delta H_{m}{ }^{\mathrm{c}}(\mathrm{J} / \mathrm{g})$ & $X_{\mathrm{c}}^{\mathrm{d}}$ & $T_{\mathrm{c}}^{\mathrm{e}}\left({ }^{\mathrm{e}} \mathrm{C}\right)$ & $K^{\mathrm{f}} \cdot 10^{2}$ & $n^{\mathrm{f}}$ & $t_{1 / 2}{ }^{\mathrm{g}}(\min )$ & $t_{1 / 2}^{\mathrm{h}}(\min )$ \\
\hline ropPHT & 10 & 112 & $134 / 143$ & 38 & 26 & 132 & 0.20 & 2.1 & 16.1 & 16.9 \\
\hline ropPHT/MWCNT $1 \%$ & 9 & 127 & 142 & 41 & 28 & 132 & 55 & 1.5 & 1.19 & 1.16 \\
\hline ropPHT/MWCNT 3\% & 9 & 128 & 143 & 41 & 28 & 132 & 110 & 1.5 & 0.73 & 0.73 \\
\hline ropPHT/MWCNT-OH 1\% & 10 & 120.6 & $139 / 143$ & 39 & 27 & 132 & 3.8 & 1.8 & 5.10 & 5.01 \\
\hline ropPHT/MWCNT-OH 3\% & 8 & 121.5 & $139 / 143$ & 39 & 27 & 132 & 78 & 1.6 & 0.96 & 0.93 \\
\hline$b d \mathrm{PHT}$ & 9 & 125 & $142 / 148$ & 40 & 28 & 135 & 0.24 & 2.1 & 13.1 & 14.5 \\
\hline$b d$ PHT/MWCNT $1 \%$ & 8 & 133 & 148 & 44 & 31 & 135 & 13 & 1.5 & 3.06 & 3.05 \\
\hline$b d \mathrm{PHT} / \mathrm{MWCNT} 3 \%$ & 8 & 134 & 147 & 43 & 30 & 135 & 100 & 1.5 & 0.79 & 0.78 \\
\hline$b d \mathrm{PHT} / \mathrm{MWCNT}-\mathrm{OH} 1 \%$ & 8 & 128 & $142 / 147$ & 44 & 31 & 135 & 2.99 & 1.9 & 5.22 & 5.23 \\
\hline$b d$ PHT/MWCNT-OH 3\% & 8 & 128 & $142 / 147$ & 43 & 30 & 135 & 31 & 1.6 & 1.64 & 1.66 \\
\hline
\end{tabular}

${ }^{\mathrm{a}}$ Glass transition temperature from melt-quenched samples determined by DSC at $20^{\circ} \mathrm{C} \cdot \mathrm{min}^{-1}$

${ }^{\mathrm{b}}$ Crystallization temperature at cooling from the melt at $10^{\circ} \mathrm{C} \cdot \mathrm{min}^{-1}$.

${ }^{\mathrm{c}}$ Melting temperature and enthalpy determined by DSC on the second heating at $10^{\circ} \mathrm{C} \cdot \mathrm{min}^{-1}$.

${ }^{\mathrm{d}}$ Crystallinity degree calculated on the basis of a $\Delta H_{\mathrm{m}}$ value of $144 \mathrm{~J} \cdot \mathrm{g}^{-1}$ for $100 \%$ crystalline PHT.[5]

${ }^{\mathrm{C}}$ Crystallization temperature for isothermal crystallization.

${ }^{\mathrm{f}}$ Parameters of Avrami equation: $\operatorname{Ln}\left(1-X_{\mathrm{t}}\right)=K t^{n}$.

${ }^{g}$ Crystallization half-time determinated experimentally.

${ }^{\mathrm{h}}$ Crystallization half-time calculated by Avrami $(\min ), t_{1 / 2}=(\operatorname{Ln} 2 / K)^{1 / n}$. 


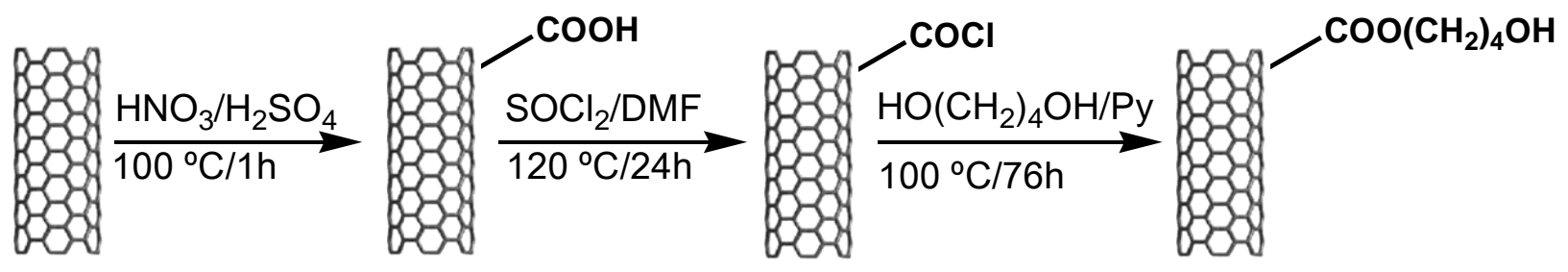

Scheme 1

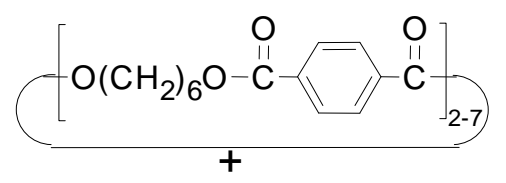

MWCNT or MWCNT-OH

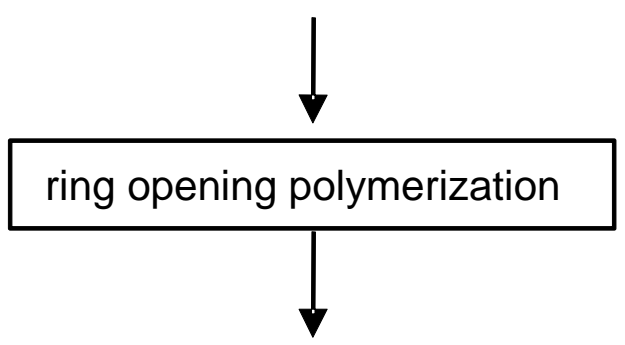

ropPHT/MWCNT or ropPHT/MWCNT-OH

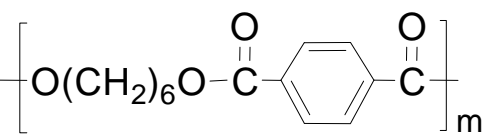

$+$ MWCNT or MWCNT-OH

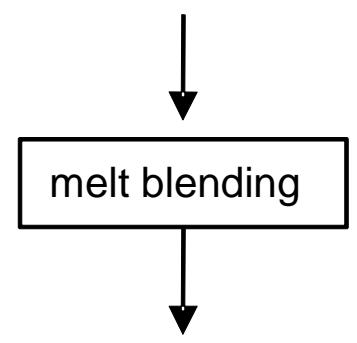

bdPHT/MWCNT or bdPHT/MWCNT-OH

Scheme 2 

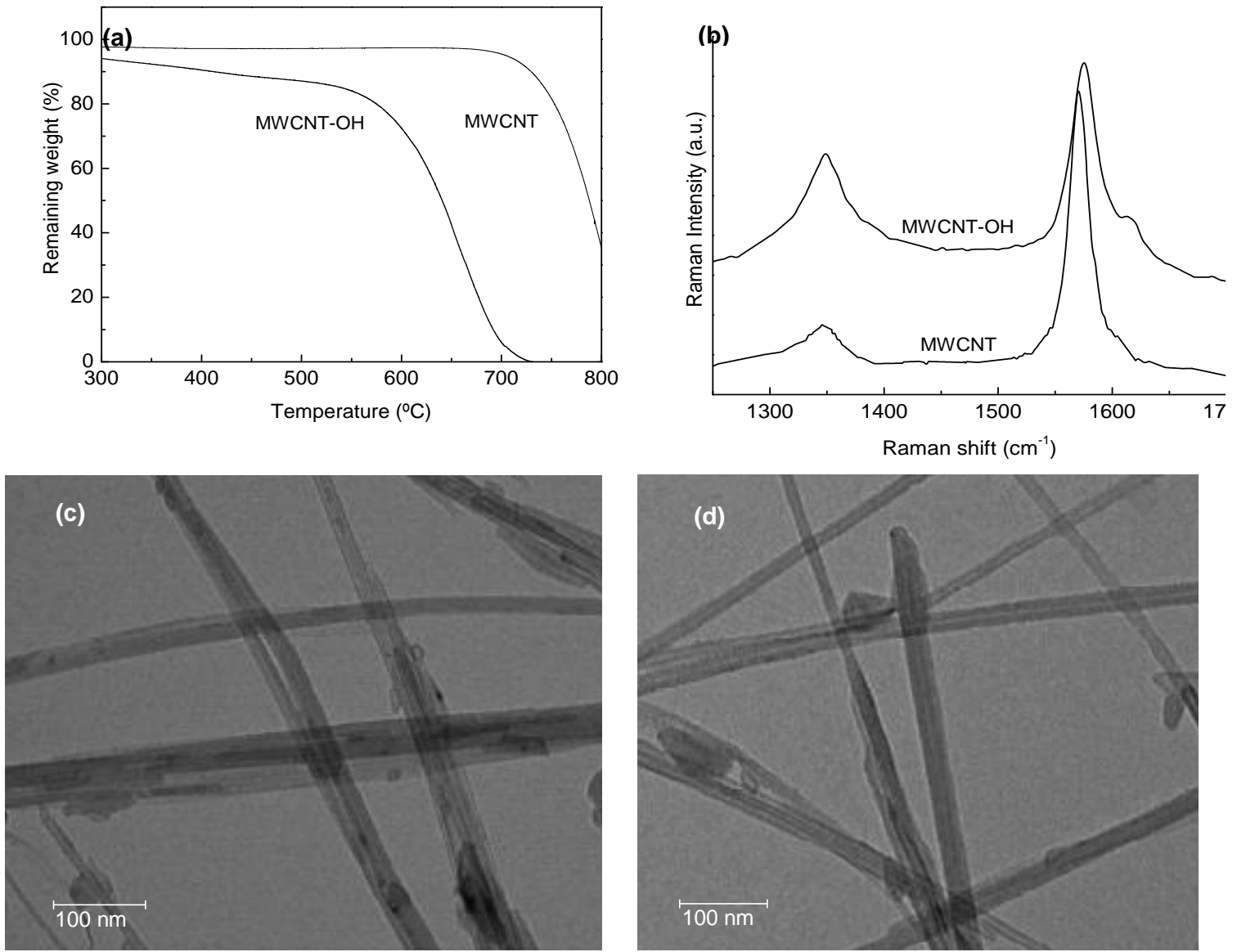

Figure 1

(a)

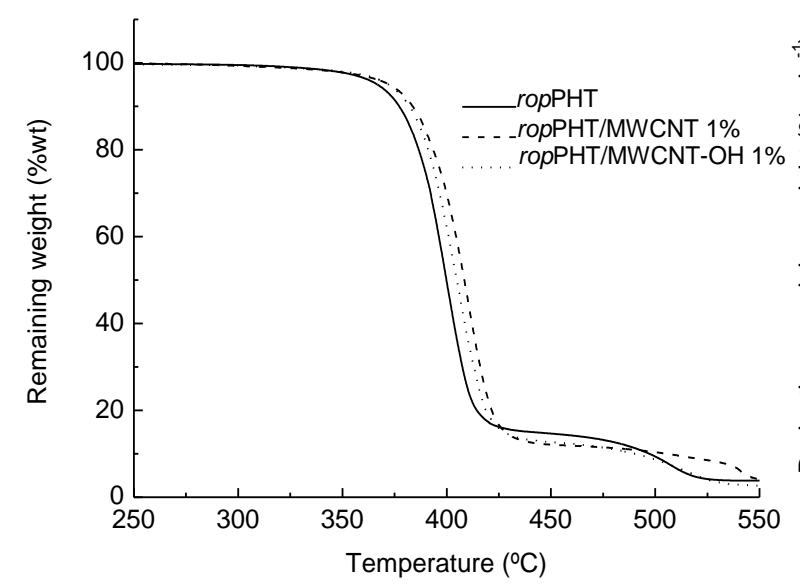

(b)

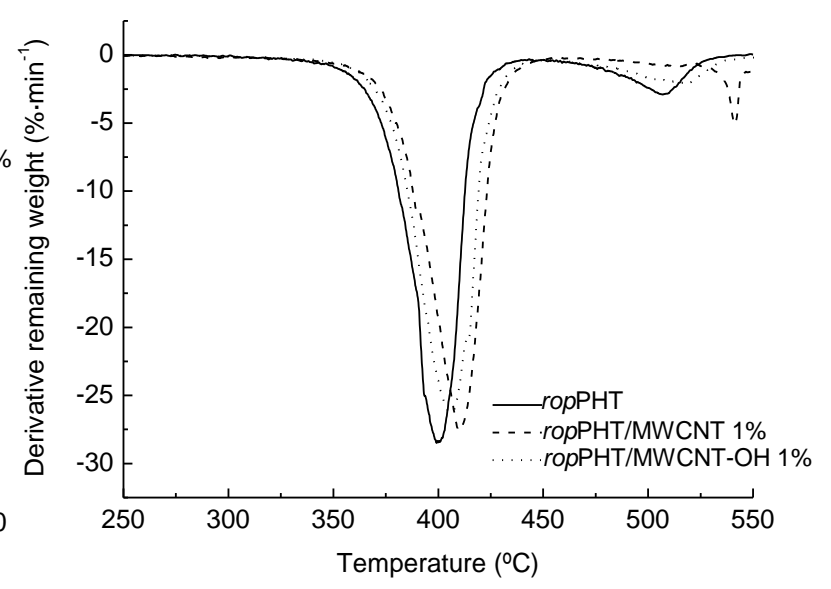

Figure 2 

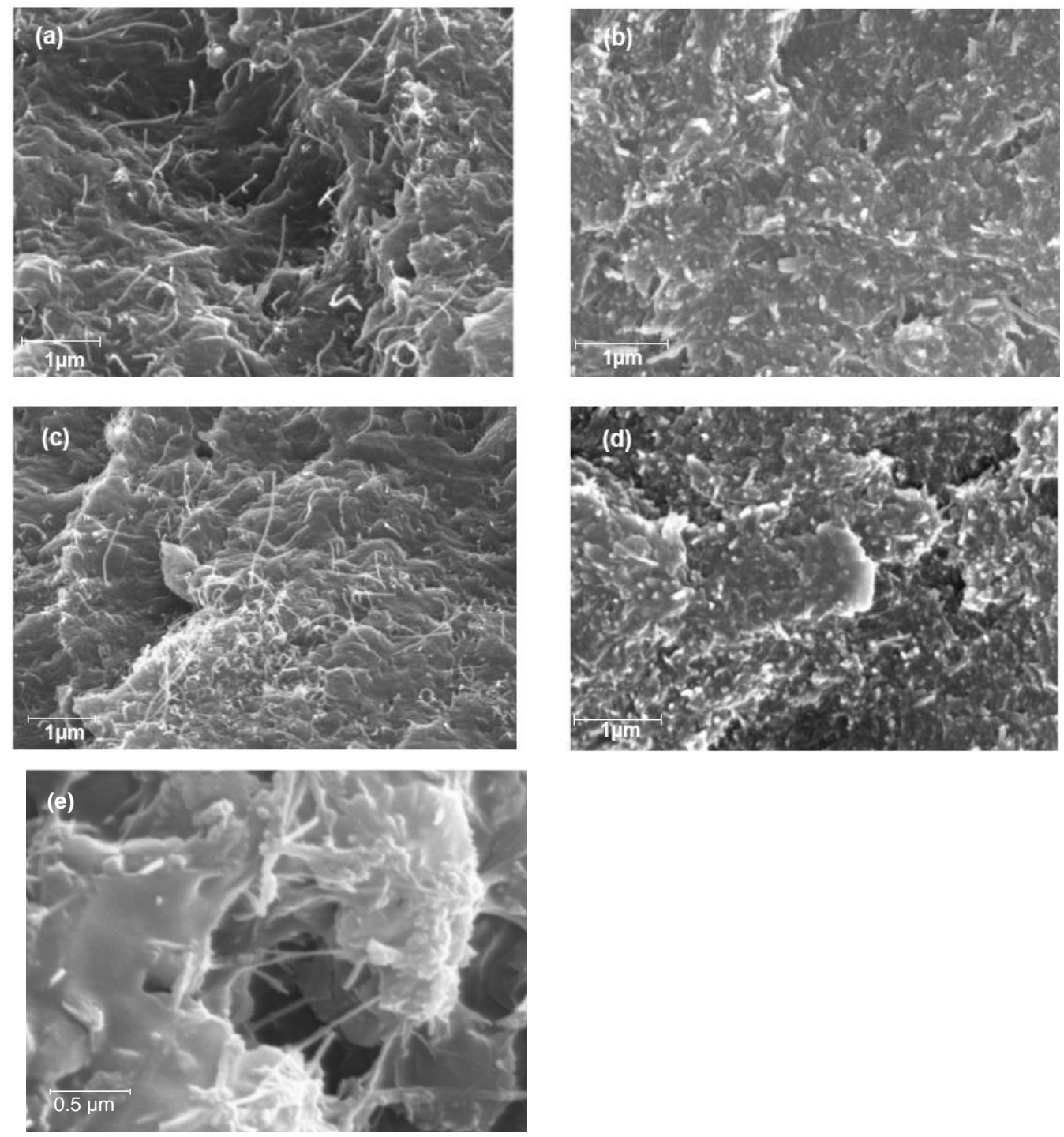

Figure 3

(a)

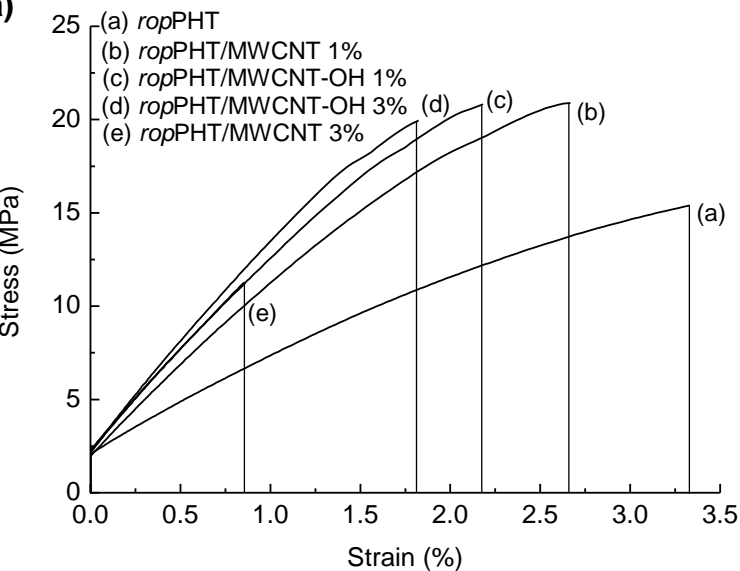

(b)

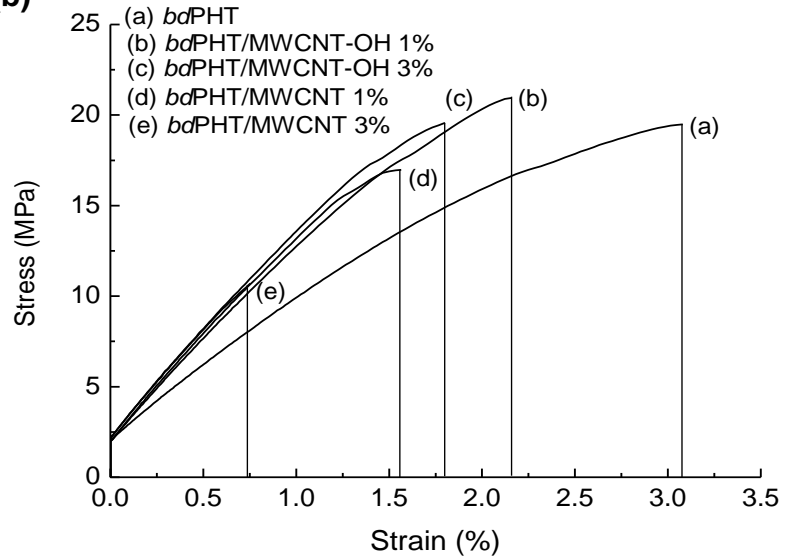

Figure 4 
(a)

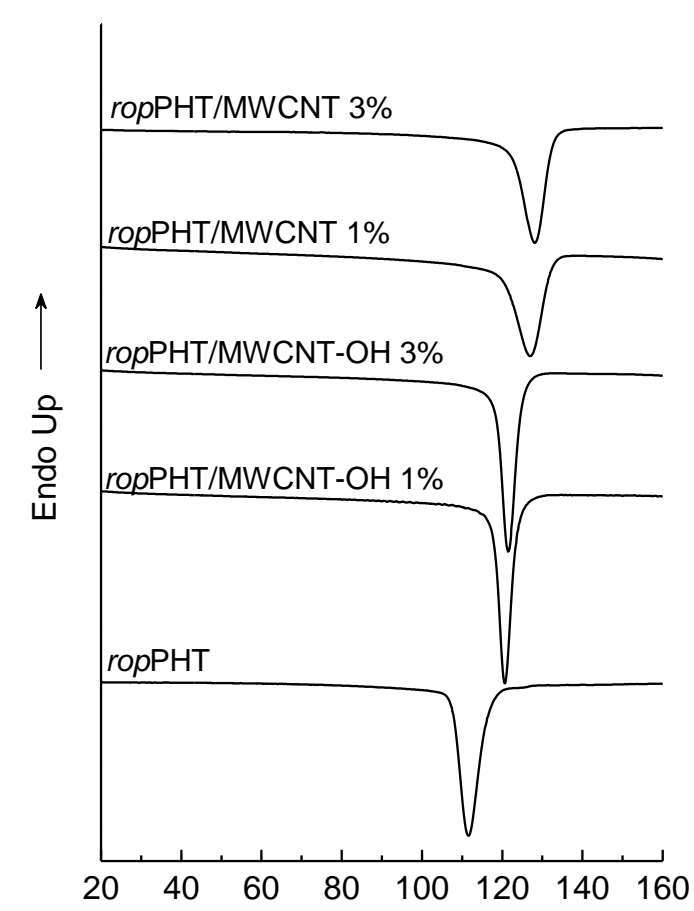

(c)

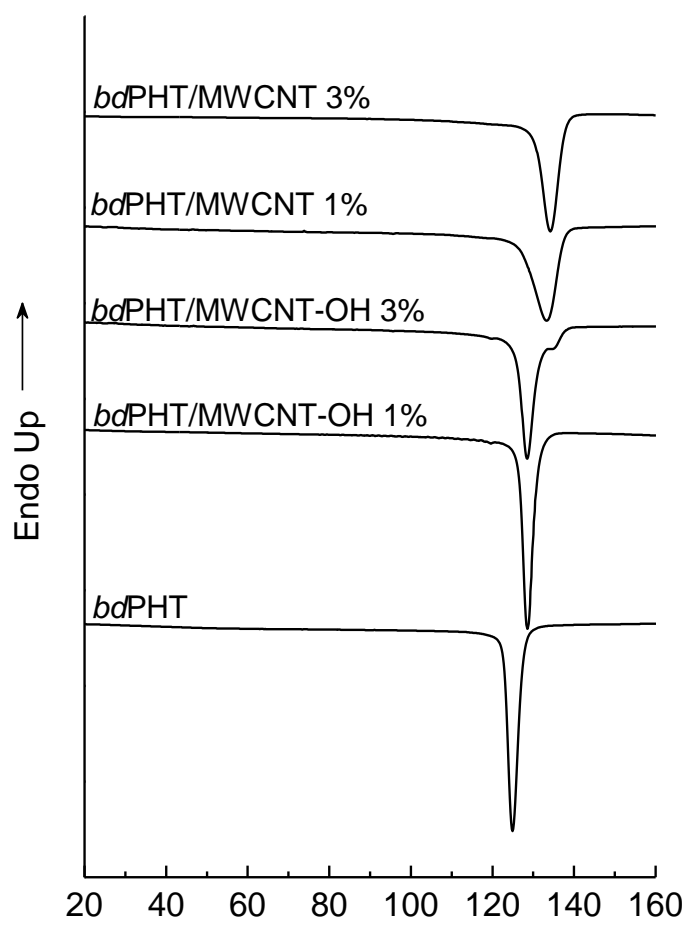

(b)

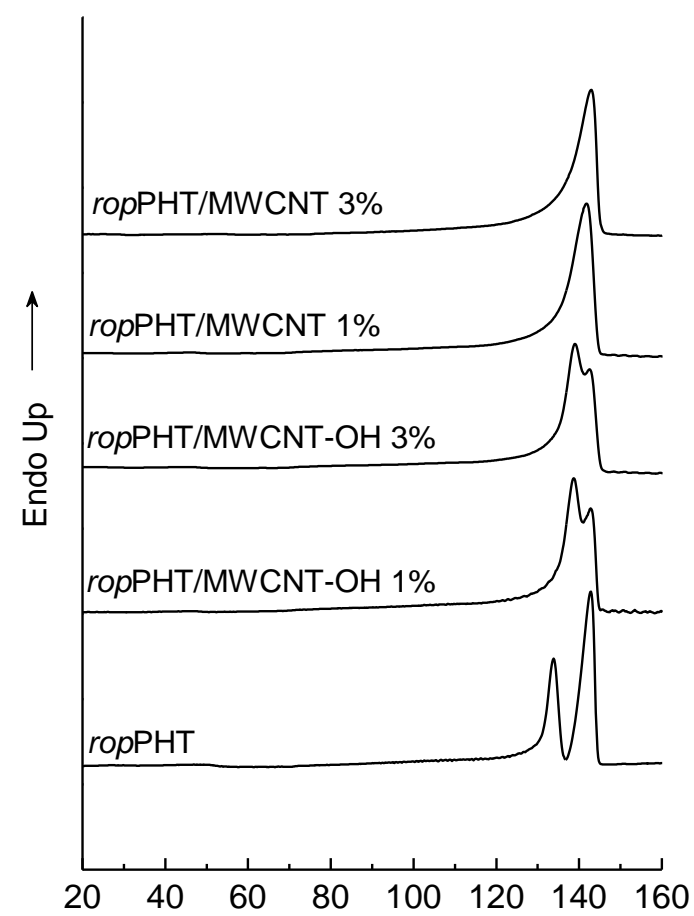

(d)

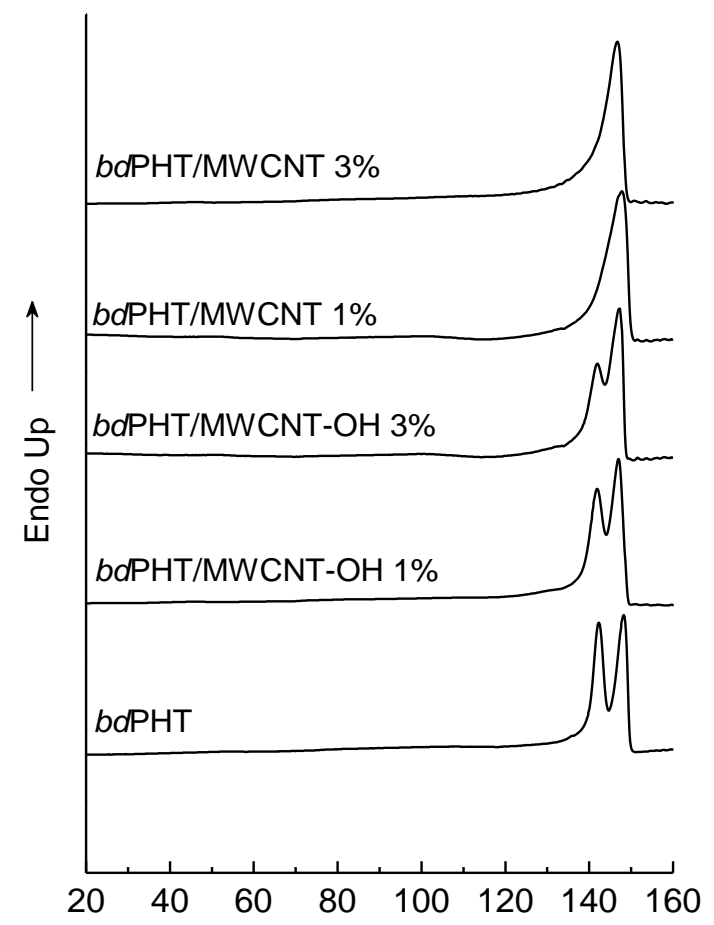

Figure 5 

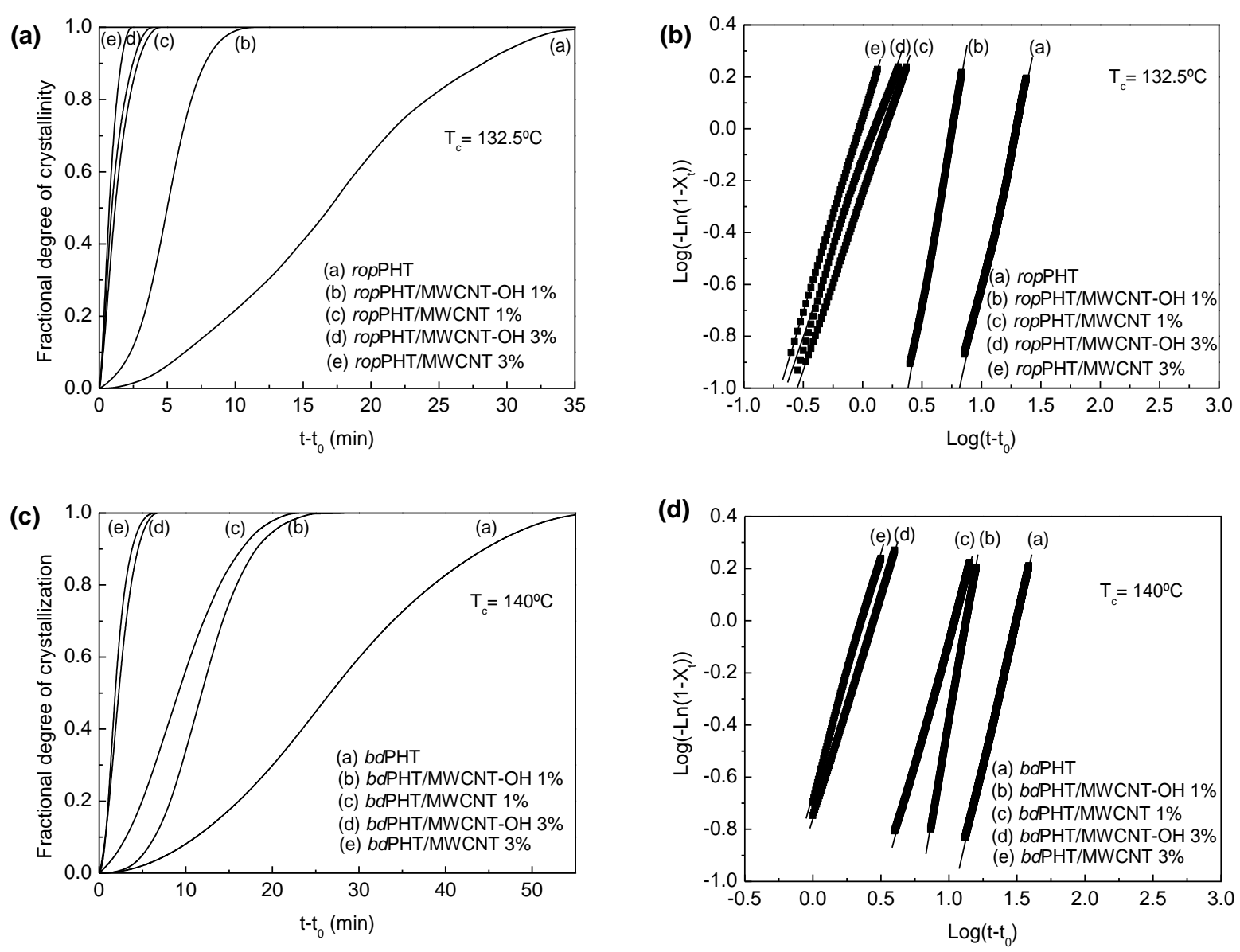

Figure 6 